\title{
Purification of Sewage Water Through the Protection of the Environment from Radioactive Contamination
}

\author{
Emad Y. Moawad \\ Faculty of Engineering, Ain shams University, Cairo, Egypt \\ *Corresponding Author: emadmoawad@hotmail.com
}

Copyright (C 2013 Horizon Research Publishing All rights reserved.

\begin{abstract}
There is a double need for better ways of processing both of the radioactive waste water and sewage water. This presentation aims to get rid of the risks of the radioactive wastes instead of being isolated from the environment besides to sewage-water purification. By utilizing transmutation of the radioactive waste products (RWP) in growing the biological cultures contained in sewage-water into stable isotopes of chemical elements to be isolated, protect the environment from the radiation contamination and sewage-water would be purified to be valid once again. During the primary stage of sewage-water purification, RWP dose is added to be transmutated into stable isotopes of chemical elements through growing the associations of the biological cultures contained in this stage. The transmutated active radionuclide should be selected of half-life time less than half the applied primary stage duration and allow the possibility to replace Calcium of the biological cells. Those organisms will react in primary stage by re-programming specific cell functions that may confer resistance to radiation. The radiation burden (Decay energy/cell) of the transmutated RWP dose is the measure of the internal adaptation for the mutagene change occurred in the biological culture. Thus, estimating the required activity of RWP should takes into account that the energy of the administered RWP dose should not exceeds that of the associations of the biological cultures contained in the primary stage. After reaching the NBR level and sedimentation of transmutated RWP for reprocessing, sewage-water should be discharged to the second stage. In the second stage, the bacteria and protozoa consume biodegradable soluble organic contaminants. The biomass grows on media and the sewage passes over its surface prior to discharge to third treatment. In the final treatment a physical disinfection through a nuclear transmutation by electric current passes through the sewage to cause electro-coagulation of the contaminants to separate precipitates from waste water by an electro-magnetic filtering unit.
\end{abstract}

\footnotetext{
Keywords Deinococcus Radiodurans, Nuclear transmutation, Microbial Catalyst-transmutator, Growth energy, Emad formula.
}

\section{Introduction}

Existing methods of reprocessing of radioactive waste products (RWP) do not solve a problem of their final removal from biosphere. At present, the main ways of neutralization of the RWP are various methods of concentrating of them into a solid state ${ }^{[1]}$ to safe it in mountain structures and an expectation of spontaneous decay. For example, $90 \mathrm{Sr}$ and $137 \mathrm{Cs}$ are necessary to store in controllable conditions about $300-600$ years [1]. There is an alternative way to transform RWP into stable or short-lived isotopes by the irradiation of the RWP by beams of neutrons and/or the charged particles $[1,2]$. This phenomenon is known as nuclear transmutation. Since the processed waste water must be quite free of radioactive contaminants if it is to be released to the environment, the radioactive material extracted from the waste water during processing must be stable or in a form that can be stabilized for disposal in a way that meets disposal site requirements, particularly with respect to preventing the leaching out of radioactive contaminates by liquid water. Finally, the volume of the waste must be minimized because of both, the limited space available for disposal of radioactive waste, and the high cost of its disposal [2]. There were numerous evidences that the nuclear transmutations were indeed taking place in life organisms of all types. Some scientists had a life-long interest in the possibility of biological transmutations, actually observations have been made for almost 200 years that elemental transmutations were occurring, but little credence was given to them because they resembled alchemy --- a relic of the idle ages [3]. Yet, none of these latter-day alchemists could propose a theory for the mechanism of such an unlikely appearing event as biological transmutation [4]. In 1928, studies conducted for more than 10 years on the production of iodine by algae. On 1962 Louis Kervran concluded in his book Biological Transmutations [3] that "It is obvious, for example, that special procedures should be applied for the measurements related to energy balances. These measurements are very complicated. Known calorimetric methods cannot be applied, because neutrinos intervene, as we are here in the domain of weak interactions. Neutrinos interact only very seldom with matter, A large part of the energy is carried away under a virtual form, so to 
speak. It goes through space without affecting our senses or our measurement instruments. How can we measure it? The future alone will tell" No information has been discovered as to the energy required for these reactions to occur and, thus, whether there would be a net gain of energy. Vysotskii, V., et al. showed a successful experiments on utilization of high-activity waste in the process of transmutation in growing associations of microbiological cultures, in tenth international conference on cold fusion $2003^{[5]}$. Microbial catalyst-transmutator" MCT like deinococcus radio durance as well as the biological cultures are capable of sustaining normal metabolism and withstanding considerably lower doses at radiation levels of over 1-10 Mrad . Because of that, a growing culture can use radioactive isotopes, present in the nutrient medium, to sustain its vital activity (its metabolism) as it can extract them selectively from different media through the process of metabolism. Moreover, there is information suggesting the important role of radioactive elements in metabolism of live objects. Due to this vital part played by the bacterial culture in absorbing the radioactive isotopes as well as the stable ones [3-5], the hope is provided for better ways of processing radioactive waste water containing suspended solids and dissolved ions from nuclear power reactors and other sources. Recently, Moawad derived the relation between the disintegration energy of the radioactive isotope and its decay constant $\left[\frac{d A}{d N}\right.$ Isotope $]$ as well as the relation between the growth energy of the biological cell and its growth constant $\left[\frac{d G}{d C_{\text {BiologicalCell }}}\right][6]$, to express both types of energies in the same unit as follows:

$$
\begin{gathered}
\mathrm{E}_{\text {D.Isotope }}=\ln \left(\left(\ln \left(\frac{\mathrm{dA}}{\mathrm{dN}}\right)_{\text {Isotope }}\right)^{2}\right) \operatorname{Emad}[6](1.1), \\
\mathrm{E}_{\text {G. Cell }}=\ln \left(\left(\ln \left(\frac{\mathrm{dG}}{\mathrm{dC}}\right)_{\text {Isotope }}\right)^{2}\right) \operatorname{Emad}(1.2)[6]
\end{gathered}
$$

where $\mathrm{A}$ is the activity of the radioactive isotope and $\mathrm{N}$ is the number of undecayed nuclei at any one time, while $\mathrm{G}=\mathrm{G}_{0} \times \mathrm{e}^{\frac{\ln 2}{\mathrm{t}_{\mathrm{D}}} \times \mathrm{t}}$

(1.3) is the activity of the biological culture,

$\mathrm{C}$ is the number of biological cells at any one time, to is the cell doubling time, whereas Emad is a variable unit for measuring these energies differs from one element to another depending on the mass number of that element, according to the following formula:

$$
\text { Emad }=\frac{\mathrm{c}^{2}}{\mathrm{e}} \times(\text { mass number }) \underbrace{1+\frac{\ln \left(\ln \ln \left(\frac{\mathrm{dA}}{\mathrm{In}(\text { mass number })}\right)^{2}\right.}{\mathrm{MeV}}} \mathrm{Me}
$$

From (1.3) the cell growth energy has another form in terms of the cell doubling time (tD) called Emad formula as follows:

$$
\mathrm{E}_{\mathrm{G} \mathrm{Cell}}=\ln \left[\left(\ln \frac{\ln 2}{\mathrm{t}_{\mathrm{D}}}\right)^{2}\right] \operatorname{Emad}[6-12](1.5),
$$

And by considering the Emad unit of each of the commonest safely used radioactive isotope namely Iodine- $131^{[7]}$ and the biological cell are identical as then:

$$
\operatorname{Emad}_{\text {Cell }}=23234.59 \mathrm{MeV} \text { [7-12] (1.6) }
$$

Consequently, the hope to purify both the radioactive waste water and sewage water to solve the problems of scarcity of fresh water as well as the recovery of the environmental radioactive pollution should take into account specifications of the level of radiation that result in, does not seem to have caused ill effects on the residents of the treatment area and even possibly has made them slightly more radio resistant.

\section{Methods and Materials}

Specifications that settled by Moawad has determined the maximum tolerated Emad value/cell for this reprocessing which corresponds to the effects of low dose radiation (LDR) of $<20 \mathrm{mSv}$ settled by the Committee on the Biological Effects of Ionizing Radiations of the National Research Council (BEIR)[8] to be as follows:

$$
\mathrm{LDR}=0.000538132 \mathrm{Emad} / \mathrm{cell}(1.7)[7,13] .
$$

While the natural background radiation (NBR) effects is about $10 \%$ of that of LDR effects ${ }^{[7,13]}$.

$$
\text { I.e. } \mathrm{NBR}=0.0000538132 \mathrm{Emad} / \mathrm{cell} \text { (1.8). }
$$

It is well known that sewage treatment passes by three main stages, called primary, secondary and final treatments ${ }^{[14]}$. Primary treatment in which temporarily holding of the sewage in a quiescent basin takes place where heavy solids settle to the bottom while oil, grease and lighter solids float to the surface. This research suggests the addition of the estimated dose of the RWP during this stage to be lowered to the NBR by utilizing the phenomenon of low temperature transmutation that transform the radioactive isotopes into stable elements through growing associations of the biological cultures contained in sewage during the primary stage. Estimating the required activity of RWP dose should takes into account that the energy of the transmutated RWP dose should not exceeds that of the associations of the biological cultures contained in the primary stage [13]. After reaching the NBR level, the settled and floating materials are removed and the remaining liquid may be discharged or subjected to secondary treatment. Reprocessing the removed waste of the primary stage is the potential use of transmutation of radioactive wastes in biological cultures into stable ones in production or selective extraction of certain radioisotopes with a very high degree of radiochemical (and chemical) purity such as isotopes of 
technetium, gallium, iodine and others [5]. Secondary treatment in which the biological content of the sewage is substantially degraded using aerobic biological processes by the biotas before discharging to the third stage. Third or final treatment in which a separation process to the micro-organisms from the treated water using nuclear transmutation $[1,2]$ to be removed by filtration. This can be summarized in adjustment the water $\mathrm{pH}$ - to be 6 to 8 - and conductivity before permitting for an electric current [2] to pass through the waste water to transform RWP into stable or very short-lived isotopes due to irradiation of the RWP by the charged particles. In the same time it causes electro-coagulation of the contaminants and anodes should be made of a metal that dissolves to provide cations [2, 14] for neutralizing the negative charges and forming precipitates containing neutralized contaminants. This process helps for the enlargement of precipitate particles to improve the dewater ability, and/or enhancement of magnetism. Efficient filtration to the treated water requires physical disinfection to precipitates are then separated from waste water by an electro-magnetic filtering unit before it is discharged to the receiving environment (sea, river, lake, ground, etc) [2].

\subsection{Estimating the Required Radioactive Doses for Transmutation Occurrence in Biological Culture During the Primary Stage}

In estimating the minimum required dose from a decaying system [radioactive isotope] that is necessary to be transmutated in the biological cells of a growing system, Moawad showed that the total decay energy of such nuclear transmutation should be less than the growth energy of the biological culture [8]. In such a case, the work done against the biological culture growth is equal to the loss in radiation energy or the decay energy of the used dose ${ }^{[15]}$.

As it is believed that cell hypoxia contributes significantly to resist traditional chemical disinfection. This happens for at least two reasons: First, most agents cannot penetrate beyond 50-100 micrometers from capillaries [16, 17], therefore never reaching the cells in the hypoxic regions. Second, the lower nutrient and oxygen supply to cells in the hypoxic zones causes them to divide more slowly than their well-oxygenated counterparts. Therefore, hypoxic cells exhibit greater resistance to chemical treatments, as well as radiation that targets rapidly dividing cells or requires oxygen for efficacy [17]. Consequently, if the percentage of the hypoxic cells is (h) \%, the work done (W) against the biological culture growth can be calculated as the total growth energy of the hypoxic cell , as follows: From (1.2)

$$
\mathrm{W}=-\mathrm{h} \% \int_{\mathrm{C}_{0}}^{0} \ln \left(\ln \frac{\mathrm{dG}}{\mathrm{dC}}\right)_{\text {Bio Cells }}^{2} \mathrm{dC}[22] \Rightarrow
$$

$$
\mathrm{W}=\ln \left(\ln \frac{\mathrm{dG}}{\mathrm{dC}}\right)_{\text {Bio.Cell }}^{2} \times \mathrm{C}_{0} \times \mathrm{h} \% \text { Emad }
$$

where, $\mathrm{C}_{0}$ is the initial number of the biological cells, $\mathrm{h}$ is the percentage of the hypoxic cells, and $\ln \left(\ln \frac{d G}{d C}\right)_{\text {Bio.Cell }}^{2}$ is the biological cell growth energy in Emad unit.

Thus, the required decay energy of the RWP $\left(\mathrm{E}_{\mathrm{RWP}}\right)$ should be equivalent to the work done (W) against the biological culture growth according to the concept of WEP.

From (2.1.1), (1.5) and (1.4)

$$
\begin{array}{r}
\mathrm{E}_{\mathrm{RWP}}=\ln \left[\left(\ln \frac{\ln 2}{\mathrm{t}_{\mathrm{D}}}\right)^{2}\right] \times \mathrm{C}_{0} \times \mathrm{h} \% \times \\
23234.59 \mathrm{MeV}(2.1 .2)[6-12],
\end{array}
$$

where $t_{D}$ is the doubling time of the biological cell.

As conducted and described by Vysotskii, V., et al. on utilization of high-activity waste in the process of transmutation in growing associations of microbiological cultures [5]; In prototype of quiescent basins of sewage treatment filled with sewage in primary stage contained Microbial Catalyst Transmutator (MCT) $\left(1 \times 10^{7} \mathrm{Cells} / \mathrm{g}\right)$ was placed with extracted water from the active zone of an atomic reactor by ratio $1: 10(1 \mathrm{~g}: 10 \mathrm{~mL})$ for the temporarily holding of the sewage to allow heavy solids to settle down to the bottom while oil, grease and lighter solids float to the surface. This ratio has been settled according to the presented mathematical model by Moawad for the deactivation impact of different radionuclides on the mechanism of the biological culture growth. The radioactive water contained highly active isotopes (e.g., Na-24, K-40, Co-60, Sr-91, I-131, Xe-135, Ba-140, La-140, Ce-141, and Np-239) with total activity about $10^{-4} \mathrm{Curie} / \mathrm{L}$. Initial activity of the Ba-140 isotopes on the 10th day after extraction of water from the active zone of the nuclear reactor was $A_{\mathrm{Ba}-140}=$ $1.46 \times 10^{-7} \mathrm{Ci} / \mathrm{L}$. Activity of quiescent basin with Ba140 had been measured during 30 days every 5 days.

\section{Results}

Results of this experiment show that enough Ba-140 was lost anomalously, Elemental transmutations accompanied by losses in mass converted to thermal energy were observed. Such energy probably is a net gain when compared to the amount required to effect the transmutation. Typical reaction of the association for such aggressive effects demands the existence of some time for internal adaptation. This time is necessary for mutagene change of 5-10 generations that corresponds to several days. Thereby the average MCT 
doubling time is between $\frac{10}{5 \rightarrow 10} \approx 1.5$ days. The possible way of radioactive $\mathrm{Ba}-140$ isotope transmutation to the stable state is $\mathrm{Ba}_{140}+\mathrm{C}_{12}=\mathrm{Sm}_{152}+\Delta \mathrm{E}$, where $\Delta$ $\mathrm{E}$ is a thermal energy equivalent to $8.5 \mathrm{MeV}$ [5].

From (1.6), $\Delta \mathrm{E}$ can be converted to the Emad unit of the biological cell as follows:

$$
\Delta \mathrm{E}_{\mathrm{Ba} \rightarrow \mathrm{Sm}}=8.5 \mathrm{MeV} / 23234.59=0.00036583387 \mathrm{Emad}(3.1) .
$$

Consequently, from (1.7), (1.8), and (3.1) it can be deduced that, the transmutation of Barium into Samarium in growing the biological cells induces growth energy above the NRB effects but less than the LDR effects.

Then the total decay energy of the added RWP from Barium was as follows:

The natural decay energy of $1.46 \times 10^{-7}$ Curie/L of Ba-140 of half-life time $\left(t_{1 / 2}\right) 12.7$ days [15] was:

$$
\begin{aligned}
& \mathrm{E}_{\text {D.Ba-140}}=1.46 \times 10^{-7} \times 3.7 \times 10^{10} \times \frac{12.7 \times 24 \times 60 \times 60}{\ln 2} \\
& \times \frac{8.5 \mathrm{MeV}}{6.242 \times 10^{12}}=0.011645106 \text { Joules }
\end{aligned}
$$

Accordingly, the radiation burden on cell $\left(R_{B}\right)$ induced by Barium dose during the experiment period $\left(\mathrm{E}_{\mathrm{D}} \times\right.$ $\left(1-\mathrm{e}^{\frac{-\ln 2}{t_{1 / 2}} \times T}\right)$

$$
\mathrm{R}_{\mathrm{B}}=0.011645106 \times 6.242 \times 10^{12}\left(1-\mathrm{e}^{\frac{-\ln 2}{12.7} ? 0}\right)
$$

$$
\div\left(100 \times 10^{7}\right)=58.55 \mathrm{MeV}(3.3) \text {. }
$$

From (1.6) and (1.7), $\mathrm{R}_{\mathrm{B}} / \mathrm{LDR}=4.68$ which is considered the measure of the internal adaptation for the mutagene change occurred in the biological culture during the primary stage which should be last until the unabsorbed RWP of the added dose reach the NBR effects.

The growth energy of the MCT $(100 \mathrm{~g} / \mathrm{L})$ in the sample can be calculated from (2.1.1) by knowing cell doubling time (tD $=1.5$ days), number of cells $\mathrm{C}_{\mathrm{o}}=10^{7}$ cells $/ \mathrm{g}$, whereas percentage of hypoxic cells ( $\mathrm{h} \%$ ) which is taken on average of $10 \%$ as follows:

$$
\begin{array}{r}
\mathrm{E}_{\mathrm{MCT}}=100 \times 10 \% \times 10^{7} \times \ln \left(\ln \frac{\ln 2}{1.5 \times 24 \times 60 \times 60}\right)^{2} \times \frac{23234.59}{6.242 \times 10^{12}} \\
=1.85743 \text { Joule (3.3), }
\end{array}
$$

which is greater than ED of the added RWP in the experiment $(0.012 \mathrm{~J}$ for Ba-140) to conclude the necessary conditions for inducing transmutation in the biological cultures; (1) the total decay energy of the nuclear transmutation should be less than the $\mathrm{E}_{\mathrm{G}}$ of the biological culture. (2) Cells adapt themselves internally to sustain the ED /cell, where such ability can be increased through several irradiation processes [18].

\section{Discussion}

The main objective of this research is to find out better ways of processing radioactive waste water containing suspended solids and dissolved ions from nuclear power reactors and other sources. The possibility of using of cold fusion for nuclear waste products transmutation is investigated to produce or to select the extraction of certain radioisotopes with a very high degree of radiochemical (and chemical) purity to be used once again. It appears quite promising to produce isotopes such as technetium, gallium, iodine, and others ${ }^{[5]}$, which is considered another potential use of the transmutation process, where production of those radionuclides is currently quite expensive due to the need of high degree of their radiochemical purity. In addition, cold fusion for elemental transmutation allows fine purifying the regenerated uranium on the final stages of its separation from products of decay to a level, allowing it to be used for prefabrication of HPE's without using heavy chambers and remote controls ${ }^{[1,5]}$. It allows also the purification of gaseous exhausts of NPP's and other facilities, processing SNF, from isotopes of noble gases and products of their decay (mainly, iodine) $[3,5]$. The other goal of this thesis is to purify sewage-water and considering its primary stage as a natural source of the microbiological systems required for cold fusion of RWP. Primary treatment involves the growing associations of microbiological cultures which contain many thousand kinds of different microorganisms in the state of complete symbiosis act as MCT [5]. MCTs are special granules include concentrated biomass of metabolically active microorganisms, and gluing substances which keep all components in the way of granules stable in water solutions for a long period of time at any external conditions. Primary treatment is designed to remove organic and inorganic solids by the physical processes of sedimentation and flotation. Primary treatment devices reduce the velocity and disperse the flow of wastewater to $1 \rightarrow 2$ feet per minute to maintain a quiescent condition so that the material denser than water will settle out and material less dense than water will float to the surface. Estimating the RWP dose added to the primary stage take into account that its $E_{D}$ is less than $\mathrm{E}_{\mathrm{G}}$ of the biological culture contained in the sewage-water and the $R_{B}$ can be sustained by the biological cells. Those organisms will react in primary stage by re-programming specific cell functions that may confer resistance to radiation ${ }^{[18]}$. The proper activity of the radioactive wastes of low level activity that are discharged from primary to second stage should be administered such that the initial energetic radiation should be less than that of biological culture growth. $R_{B}$ can be increased through irradiation cells several times 
which increases the radioresistant capability of cells ${ }^{[18]}$. Selection of Barium for the provided experiment was due to its suitable half-life time (12.7 days) which is less than half the duration of the applied primary stage (30 days) and to the possibility of Barium to replace Calcium of the biological cells. Transmutation of Barium into Samarium occurs in the biological cells results in the $\mathrm{Sm}^{2+}$ and $\mathrm{Ca}^{2+}$ ions which are chemically alike and have the approximately same ionic radii of divalent state $\left(\mathrm{R}_{\mathrm{Sm}} \approx 1.2 \mathrm{~A}, \mathrm{R}_{\mathrm{Ca}} \approx 1.06 \mathrm{~A}\right)$. Substituted element $\mathrm{Ca}$ is among several vitally necessary elements. Ions of created $\mathrm{Sm}^{2+}$ elements can substitute $\mathrm{Ca}^{2+}$ ions while microbiological cultures are growing [5, 19]. The probability of such substitution during the process of growing of a biological culture is high because the initial concentration of $\mathrm{Ca}$ element in MCT is low. The results of all the provided experiment are consistent with the existence of radiation being essential to induce nuclear transmutation (NT) in the biological bodies. Measuring the biological $\mathrm{E}_{\mathrm{G}}$ in $\mathrm{MeV}$ or Joules, allows to asses the limits of energy that is suitable for the treatment purpose. From data of the experiment shown in section 2.1, the accumulated released energy from Ba-140 during 30 days $(0.012 \mathrm{~J})$ was less than the $\mathrm{E}_{\mathrm{G}}$ of MCT $(1.85 \mathrm{~J})$, to confirm the necessary condition for transmutation to be induced in the biological cultures and achieve significantly higher influence upon the spontaneous decay characteristics; the total decay energy of the NT should be less than the $E_{G}$ of the biological culture, and in the same time, the $\mathrm{E}_{\mathrm{G}}$ of the biological cell should be greater than that produced by these reactions to allow their occurrence within the cell [13]. The duration of the primary stage which is the longest period, should be enough for reaching the level of NBR [5], the settled and floating materials are removed and the remaining liquid may be discharged or subjected to secondary treatment ${ }^{14,20]}$. After discharging sewage-water to the second stage, the reprocessing of the biomass sediment waste starts to extract certain radionuclides with a very high degree to be used once again. While the duration of each that of the second and third stage are very short compared to the first two durations. The second stage is designed to substantially degrade the biological content of the sewage, where the majority of municipal and industrial plants treat the settled sewage liquor using aerobic biological processes. For this to be effective, the biotas require both oxygen and a substrate on which it lives ${ }^{[14,20, \text { and } 21]}$. There is a number of ways in which this is done. In all these methods, the bacteria and protozoa consume biodegradable soluble organic contaminants. The biomass grows on media and the sewage passes over its surface. In suspended growth systems - such as activated sludge - the biomass is well mixed with the sewage. These microorganisms appertain to different physiological groups that represent practically the whole variety of the microbe metabolism and relevantly all kinds of microbe accumulation mechanisms. At this stage secondary treatment may requires a separation process to remove the micro-organisms from the treated water prior to discharge to final treatment. The growing associations of microbiological cultures which are considered as MCT [5] that contain many thousand kinds of different microorganisms that are in the state of complete symbiosis, act as special granules that include: concentrated biomass of metabolically active microorganisms, and gluing substances which keep all components in the way of granules stable in water solutions for a long period of time at any external conditions. The state of complete symbiosis of the syntrophin associations results in the possibility of maximal adaptation of the microorganisms' association to any external conditions changes including effect of highly active ionizing irradiation [2, 22-25]. Microorganisms' interaction with metals is manifested through its final result, these microorganisms that are remained after passing by the activated sludge suspended under sewage surface which regarded for shortage of oxygen supply as hypoxic cells, where hypoxia occurs when obtaining oxygen from media of low oxygen content $[16,17]$ e.g. Underwater- that control the amount of oxygen in the supplied air, as it is believed that cell hypoxia contributes significantly to treatment failure because cells in the hypoxic zones resist traditional chemical disinfection for at least two reasons: first, most agents cannot penetrate beyond 50-100 micrometers from capillaries[16], thereby never reaching those cells in the hypoxic regions. Secondly, the lower nutrient and oxygen supply to cells in the hypoxic zones of cause them to divide more slowly than their well oxygenated counterparts, so hypoxic cells exhibit greater resistance to chemical treatments as well as radiation which target rapidly dividing cells or require oxygen for efficacy [17], then it is recommended to increase the amount of oxygen through the whole layers of sewage by using a mechanical method like air pumps. The final step in the secondary treatment stage is to settle out the biological floc or filter material and produce sewage water containing very low levels of organic material and suspended matter. Concerning the third or final treatment, the treated water require a physical disinfection as well as a nuclear transmutation $[1,2,26]$, which can be summarized in adjustment the water $\mathrm{pH}$ and conductivity before permitting for an electric current to pass through the waste water ${ }^{[2]}$ to transform RWP into stable or very short-lived isotopes due to irradiation of the RWP by the charged particles where if the water is acidic (lower than 7), lime, soda ash, or sodium hydroxide is added to raise the $\mathrm{pH}$. For somewhat acidic, alkaline waters (lower than 6.5), forced draft degassifiers are the cheapest way to lower the $\mathrm{pH}$, as the process raises the $\mathrm{pH}$ by stripping dissolved carbon dioxide (carbonic acid) from the water. Lime is commonly used for $\mathrm{pH}$ adjustment for municipal water, or at the start of a treatment plant for process water, as it is cheap, but it also increases the ionic load by raising the water hardness [2, 22-25]. Making the water slightly alkaline ensures that coagulation and flocculation processes work effectively for enlargement of precipitate particles, improvement of filtration, improvement of dewater ability, and/or enhancement of magnetism [2,14, 20], especially in the presence of the electric current which pass through the waste water and also helps to minimize the risk of lead being dissolved from lead pipes and lead solder in pipe fittings. Acid $\left(\mathrm{HCl}\right.$ or $\left.\mathrm{H}_{2} \mathrm{SO}_{4}\right)$ may be added to alkaline waters in some circumstances to lower the $\mathrm{pH}$. Having an alkaline 
water does not necessarily mean that lead or copper from the plumbing system will not be dissolved into the water but as a gengenerality, water with a $\mathrm{pH}$ above 7 is much less likely to dissolve heavy metals than a water with a $\mathrm{pH}$ below 7 . As the electric current is passed through the waste water it causes electro-coagulation of the contaminants and anodes are made of a metal that dissolves to provide cations for neutralizing the negative charges and forming precipitates containing neutralized contaminants ${ }^{[1,2]}$. Precipitates are then separated from waste water by an electro-magnetic or other filtering unit [2]. As it causes these neutralized particles to flocculate and form a type of flocculent (floc), more readily filterable, and thus de-waterable $[14,20]$. Moreover, the anode and cathode will hydrolyze water molecules, liberating oxygen and hydrogen [2], respectively, as tiny bubbles, the latter combining with many of the dissolved ions in the water to form insoluble oxides. The oxygen and hydrogen also will cause small, light biological particles such as bacteria that have been destroyed during the second stage or by electro-osmotic shock to float and flocculate (e.g., oils and greases) so that they can also be skimmed off or filtered out ${ }^{[2]}$ prior to discharge into a stream, river, or it can be used for the irrigation of a golf course, green way or park. If it is sufficiently clean, it can also be used for groundwater recharge or agricultural purposes $[14,20]$.

\section{Conclusion}

Existing methods of reprocessing both of the radioactive waste products (RWP) and the sewage water can be combined together to achieve besides water purification, the transformation of waste and biomass to energy, fuels, and other useful materials (valorization) and solve the problem of RWP final removal from biosphere. With promising efficacy, lower risk, and a lower relatively affordable cost of the radioactive purification technique, this approach assessed the importance of this new technology for the environmental protection. It provides the possibility to purify the low radioactive waste in stable state or to a level provides a possibility of their burial, as non-radioactive waste at the NBR level, besides to the purification of sewage-water as well. Thus, transmutation of RWP in growing associations of the biological cultures contained in the primary stage of the sewage- water treatment is considered the hope of upcoming radiation environmental protection.

\section{Conflict of Interest}

The author declares that there is no conflict of interest concerning this paper.

\section{REFERENCES}

[1] Tsvetkov, S.A. Possibility Of Using Of Cold Fusion For
Nuclear Waste Products Transmutation. in Tenth International Conference on Cold Fusion. 2003. Cambridge, MA: LENR-CANR.org

[2] Patent application title: METHOD AND SYSTEM FOR TREATING RADIOACTIVE WASTE WATER http://www.faqs.org/patents/app/20090152203\#ixzz0ZGisZ1 xy

[3] Louis Kervran: Biological Transmutations and Modern Physics , Maloine S.A. Publisher, Paris (1982) ISBN 2-224-00831-7

[4] C. Louis Kervran: Biological Transmutations and Modern Physics Review by: Eugene Mallove, from Infinite Energy.2000; 34: 56-9

[5] Vysotskii, V., et al. Successful Experiments On Utilization Of High-Activity Waste In The Process Of Transmutation In Growing Associations Of Microbiological Cultures. in Tenth International Conference on Cold Fusion. 2003. Cambridge, MA: LENR-CANR.org.

[6] Emad Moawad. Isolated System towards a Successful Radiotherapy Treatment, Nuclear Medicine and Molecular Imaging (2010) 44:123-136.

[7] Emad Y. Moawad Radiotherapy and risks of tumor regrowth or inducing second cancer. Cancer Nanotechnology (2011) 2:81-93.

[8] Emad Y. Moawad, Clinical and pathological staging of the cancer at the nanoscale, Cancer Nano (2012) 3:37-46.

[9] Emad Y. Moawad, Reconciliation between the clinical and pathological staging of cancer. Comp Clin Pathol. 2012; DOI: $10.1007 / \mathrm{s} 00580-012-1603-6$.

[10] Emad Y. Moawad, Optimizing Bioethanol production through regulating Yeast Growth Energy, Syst Synth Biol (2012) 6:61-68

[11] Emad Y. Moawad (2013). Safe Doses and Cancer Treatment Evaluation. Cancer and Oncology Research, 1, 6 - 11. doi: 10.13189/cor.2013.010102.

[12] Emad Y. Moawad, Administering the optimum dose of L-Arginine in regional tumor therapy. Ind $\mathrm{J}$ Clin Biochem. 2013; DOI: $10.1007 / \mathrm{s} 12291-013-0379-\mathrm{Z}$

[13] Emad Y. Moawad, Mechanism of Nuclear transmutations in the Biological Culture .MPM-D.3 15:30 HPS 2011 Annual Meeting

hpschapters.org/2011AM/program/singlesession.php3?sessid $=$ MPM-D

[14] Coagulation and sedimentation in lakes, reservoirs and water treatment plants Author: O'Melia C.R.Source: Water Science and Technology, Volume 37, Number 2, 1998, pp. 129-135(7) Publisher: Elsevier

[15] Physics for scientists and engineers with modern physics seventh editionBy: SERWAY JEWETT

[16] Drug penetration in solid tumors; A. Minchinton and I. Tannock; Nature Reviews Cancer 6:583-592, 2006.

[17] Article: Mitochondrial cytochrome oxidase produces nitric oxide under hypoxic conditions: Implications for oxygen sensing and hypoxic signaling in eukaryotes

[18] de Llobet LI, Baro M, Figueras A, Modolell I, Da Silva MV, 
Muñoz P, Navarro A, Mesia R, Balart J. Development and characterization of an isogenic cell line with a radioresistant phenotype. Clin Transl Oncol. 2013; 15(3):189-97.

[19] Artisjuk V.V., Konobeev A.J., Korovin J.A., Sosnin V.N., "Burning off" long-living radioactive fission products $90 \mathrm{Sr}$ and $137 \mathrm{Cs}$ in a stream of fast neutrons", J. Atomic Energy, Vol. 71, Issue 2, August 1991, pp. 184-186.

[20] Environmental Pollution Monitoring and Control By S. M. Khopkar

[21] PERFORMANCE OF SURFACE-AERATED BASINS BEYCHOK, MILTON R CHEMICAL ENGINEERING PROGRESS, SYMPOSIUM SERIES, VOL 67, NO 107, P 322
[22] Ion exchange (D. Muraviev, V. Gorshkov, A. Warshawsky), M. Dekker, New York, 2000.

[23] F. Helfferich, Ion Exchange, McGraw Hill, New York, 1962 (Bible of the subject).

[24] Ion Exchangers (K. Dorfner, ed.), Walter de Gruyter, Berlin, 1991

[25] C. E. Harland, Ion exchange: Theory and Practice, The Royal Society of Chemistry, Cambridge, 1994.

[26] Pablo R. Castello, Pamela S. David, Travis McClure, Zachary Crook and Robert O. Poytonhttp://www.sciencedirect.com/science?_imagekey=B 7MFH-4JMTJX8-8-http://www.cell.com/cell-metabolism/ab stract/S1550-4131(06)00071- 